\title{
Effect of Tile Powder Used as a Cementitious Material on the Mechanical Properties of Concrete
}

\author{
Naraindas Bheel \\ Department of Civil Engineering \\ Mehran UET, Sindh, Pakistan \\ naraindas04@gmail.com
}

Sohail Ahmed Abbasi

Department of Civil Engineering

QUEST Campus, Sindh, Pakistan

engr.sohail63@gmail.com

\author{
Rameez Ali Abbasi \\ Department of Civil Engineering \\ Indus University, Karachi, Pakistan \\ engr.rameez13@gmail.com
}

\author{
Abdul Wahab Abro \\ Department of Civil Engineering \\ Mehran UET, Sindh, Pakistan \\ ablwab82@gmail.com
}

\author{
Samiullah Sohu \\ Department of Civil Engineering \\ QUEST Campus, Sindh, Pakistan \\ sohoosamiullah@gmail.com
}

\author{
Zubair Hussain Shaikh \\ Department of Civil Engineering \\ Mehran UET, Sindh, Pakistan \\ azubair.shaikh56@gmail.com
}

\begin{abstract}
This study was undertaken to reduce the usage of cement in concrete where different proportions of tile powder as cement replacement were used. Since in the manufacture of cement an exuberant amount of carbon dioxide is disposed of in the environment, this research aims to curtail the dependence on cement and its production. The objective of this work is to investigate the properties of fresh mix concrete (workability) and hardened concrete (compressive and splitting tensile strength) in concrete with different proportions of $0 \%, 10 \%, 20 \%, 30 \%$, and $40 \%$ of tile powder as a cement substitute. In this study, a total of 90 concrete samples were cast with mix proportions of 1:1.5:3, 0.5 water-cement ratio, cured for 7,14 and 28 days. For determining the compressive strength, cubical samples, with dimensions of $100 \mathrm{~mm} \times 100 \mathrm{~mm} \times 100 \mathrm{~mm}$, were cast, while for the determination of the splitting tensile strength, cylindrical samples with dimensions of $200 \mathrm{~mm}$ diameter and $100 \mathrm{~mm}$ height, were tested after 7, 14, and 28 days. The highest compressive strength of concrete achieved for tile powder concrete was $7.50 \%$ at $10 \%$ replacement after 28 days of curing. The splitting tensile strength got to $10.2 \%$ when concrete was replaced with $10 \%$ of tile powder and cured for 28 days. It was also shown that with increasing percentage of the tile powder content, the workability of the fresh concrete increases.
\end{abstract}

Keywords-tile powder; cement replacement material; strength increase; cement use reduction

\section{INTRODUCTION}

Concrete is the most commonly used building material in the world. It consists of two parts: paste and filler. The paste comprises cement and water and sometimes other chemical additives, where the aggregate comprises sand and gravel. The paste ties the aggregates together. Aggregates are moderately inert filler constituents which occupy $70 \%$ to $80 \%$ of the volume of concrete, therefore, it is expected to have effects on its properties [1]. For every ton of cement produced about one ton of carbon dioxide is released into the atmosphere. Cement industry production corresponds to about $5 \%$ of global anthropogenic emissions of carbon dioxide. Cement production is also related to dust, and noise [2, 3]. The necessity for more economical and environmentally friendly cement materials expanded the interest in other materials which can be used as substitutes to partially replace conventional Portland cement [4-6]. The cost of natural resources is increasing constantly, leading to the search for alternatives, such as recycled materials, rice husk ash, sawdust ash [7], silica fume, fly ash, coal bottom ash [8], marble powder, millet husk ash, etc. Also, ordinary Portland cement (OPC), is related to several diseases [9-11].

Construction industry can be the final consumer of all waste tile powder and, thus, help solve this environmental problem $[12,13]$. It is known that about 100 million tons of tiles are produced annually. Fifteen to $30 \%$ of total production is turned into waste without recycling from the tile industry. Tile powder has various advantages such as reduced cost, saving energy and reduced environment risks [14]. Tile waste can be used in concrete to increase some of its properties like strength. Various studies have been conducted on the use of by-products to increase their effectiveness $[15,16]$. Authors in [17] experimented on hardening concrete blended with $10 \%-30 \%$ of crushed tiles as replacement of coarse aggregates and 10\%$30 \%$ of granite powder used as fine aggregates. Concrete samples were prepared and tested at 7, 14, 21, 28 and 90 days. In testing, it was found that compressive and splitting tensile strength were enhanced to about $8.02 \%$ and $41.6 \%$ respectively with addition of $20 \%$ crushed tile and $30 \%$ granite powder in concrete cured for 28 days. Authors in [18] studied the hardening of concrete with inclusion of $10 \%$ and $20 \%$ waste tile powder used as a replacement of coarse aggregates and $10 \%$ and $20 \%$ of tile powder as replacement of fine aggregates. It was reported that the compressive strength was measured by $14.2 \%$ with addition of $10 \%$ waste tile powder and $20 \%$ of tile powder in concrete after 28 days. Authors in [19] investigated hardened concrete with addition of $0 \%-50 \%$ crushed ceramic tile powder as cement substituent material. The compressive strength was measured by $18.3 \%$ at 28 days by using $30 \%$ of 
crushed ceramic tile powder in concrete. The tiles were made of natural materials sintered at high temperatures. There were no damaging chemicals in the tiles. Waste tiles can only cause pollution [20]. Therefore, this study endeavors to use the tile powder produced in Pakistan as a material that replaces cement. Experimental work was carried out to find the influence of tile powder on the properties of concrete.

\section{RESEARCH METHODOLOGY}

The aim of this experimental work was to check the properties of fresh concrete (workability) and the mechanical properties of hardened concrete such as compressive and splitting tensile strength with tile powder utilized as partial cement replacement material, with various percentages, in order to quantify the influences of tile powder in concrete and to know its impact on the mechanical properties of concrete. For this reason, there were two types of specific standards samples (cube, $100 \mathrm{~mm} \times 100 \mathrm{~mm} \times 100 \mathrm{~mm}$ and cylinder $100 \mathrm{~mm}$ diameter and $200 \mathrm{~mm}$ height) were made in the Structural and Concrete Laboratory. A total of 90 concrete samples were prepared with mix ratio of $1: 1.5: 3$ in which 0.5 water-cement ratio was used and were cured for 7,14 , and 28 days as shown in Table I. Furthermore, the concrete cube samples were used for compressive strength tests and the cylindrical samples were used for splitting tensile strength tests under the British Standard (BS) code. Three specimens were cast for each proportion of tile powder and the average value was taken as the final result [6].

\section{TABLE I. CONCRETE SAMPLES DETAILS}

\begin{tabular}{|c|c|c|c|c|}
\hline Samples & $\begin{array}{l}\text { Tile powder } \\
\text { percentage }\end{array}$ & $\begin{array}{c}7 \\
\text { days }\end{array}$ & $\begin{array}{c}14 \\
\text { days }\end{array}$ & $\begin{array}{c}28 \\
\text { days }\end{array}$ \\
\hline \multirow{5}{*}{$\begin{array}{l}\text { Cube samples used for } \\
\text { compressive strength testing }\end{array}$} & $0 \%$ & 3 & 3 & 3 \\
\hline & $10 \%$ & 3 & 3 & 3 \\
\hline & $20 \%$ & 3 & 3 & 3 \\
\hline & $30 \%$ & 3 & 3 & 3 \\
\hline & $40 \%$ & 3 & 3 & 3 \\
\hline \multicolumn{2}{|l|}{ Total } & 15 & 15 & 15 \\
\hline \multirow{5}{*}{$\begin{array}{l}\text { Cylindrical samples used for } \\
\text { splitting tensile strength } \\
\text { testing }\end{array}$} & $0 \%$ & 3 & 3 & 3 \\
\hline & $10 \%$ & 3 & 3 & 3 \\
\hline & $20 \%$ & 3 & 3 & 3 \\
\hline & $30 \%$ & 3 & 3 & 3 \\
\hline & $40 \%$ & 3 & 3 & 3 \\
\hline \multicolumn{2}{|l|}{ Total } & 15 & 15 & 15 \\
\hline
\end{tabular}

\section{MATERIALS USED}

\section{A. Cement}

Locally available OPC was used in this experimental work under the brand name "Pakland". Tests were conducted on cement as given in Table II.

\section{B. Fine and Coarse Aggregates}

Aggregates were obtained from the local market in the region of Hyderabad, Pakistan. Fine aggregates passed from a $4.75 \mathrm{~mm}$ sieve for removing unwanted materials and the coarse aggregates used in this work had a size of $20 \mathrm{~mm}$. Various tests of fine and coarse aggregates were conducted in the laboratory for assuring the quality of materials as shown in Table III.
TABLE II. CEMENT TESTS

\begin{tabular}{|c|c|}
\hline Tests & Results \\
\hline Normal consistency & $33 \%$ \\
\hline Initial setting time & $45 \mathrm{~min}$ \\
\hline Final setting time & $220 \mathrm{~min}$ \\
\hline
\end{tabular}

TABLE III. PROPERTIES OF AGGREGATES

\begin{tabular}{|c|c|c|}
\hline Properties & Fine aggregates & Coarse aggregates \\
\hline Fineness modulus & 2.24 & - \\
\hline Water absorption & $1.30 \%$ & $0.54 \%$ \\
\hline Specific gravity & 2.67 & 2.63 \\
\hline Bulk density & $1201 \mathrm{~b} / \mathrm{ft}^{3}$ & $981 \mathrm{~b} / \mathrm{ft}^{3}$ \\
\hline
\end{tabular}

\section{Tile Powder}

Tile waste is generated during the finishing and polishing of tiles in the industry. This waste was collected in the form of pest and after drying, hand crushing, and sieving through \#300 sieves it can be used as cement replacement in concrete.

\section{Water}

Drinking water was used for mixing concrete in the laboratory.

\section{RESULTS AND DISCUSSION}

\section{A. Workability of Fresh Concrete}

The workability of concrete was measured with a slump cone in terms of slump reduction. The maximum slump value recorded was $88 \mathrm{~mm}$ at $40 \%$ of tile powder and the minimum value was $58 \mathrm{~mm}$ at $0 \%$ of tile powder as cement replacement. By carrying out the experimental work, it was shown that the workability of concrete gets proliferated with increasing quantity of tile powder $[18,21]$ as shown in Figure 1.

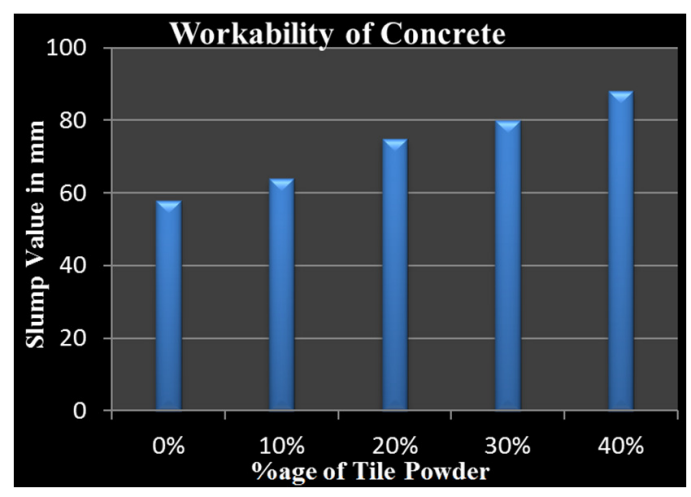

Fig. 1. Workability (fresh concrete)

\section{B. Compressive Strength of Concrete}

The cubical samples $(100 \mathrm{~mm} \times \times 100 \mathrm{~mm})$ were tested to determine the compressive strength of the concrete's various proportions of tile powder as cement replacement. At each proportion of tile powder, three concrete samples were cast and the average value was considered. The compressive strength of concrete improved by $7.50 \%$ at $10 \%$ of tile powder while it was decreased to about $12.60 \%$ when $40 \%$ of tile powder substituted cement in concrete cured for 28 days. The compressive strength of concrete was reduced at the initial 
stage of the curing period and increased at the final stages of curing period as presented in Figure 2.

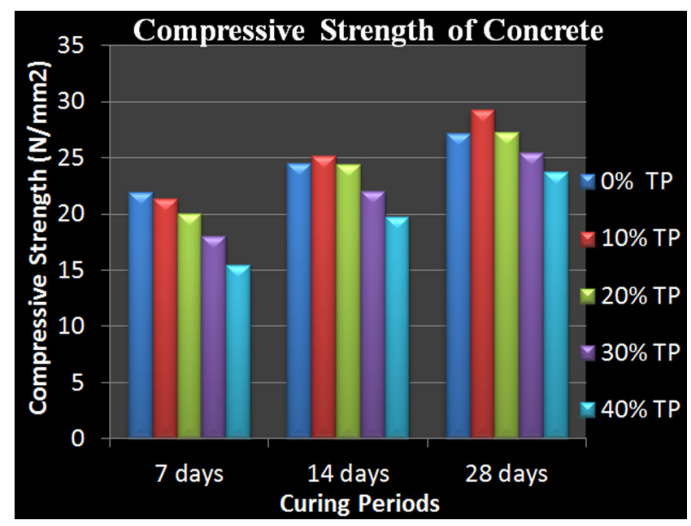

Fig. 2. Compressive strength of concrete

\section{Splitting Tensile Strength of Concrete}

The cylindrical samples were used for determining the splitting tensile strength of concrete. At each proportion of tile powder, three concrete samples were cast and the average value was considered. The splitting tensile strength improved up to $10.20 \%$ when $10 \%$ of tile powder was used and it decreased to $8.0 \%$ when using $40 \%$ of tile powder as substituent for cement in concrete cured for 28 days. The splitting tensile strength of concrete reduced at the initial stage of the curing period and increased at the final stages of the curing period as displayed in Figure 3.

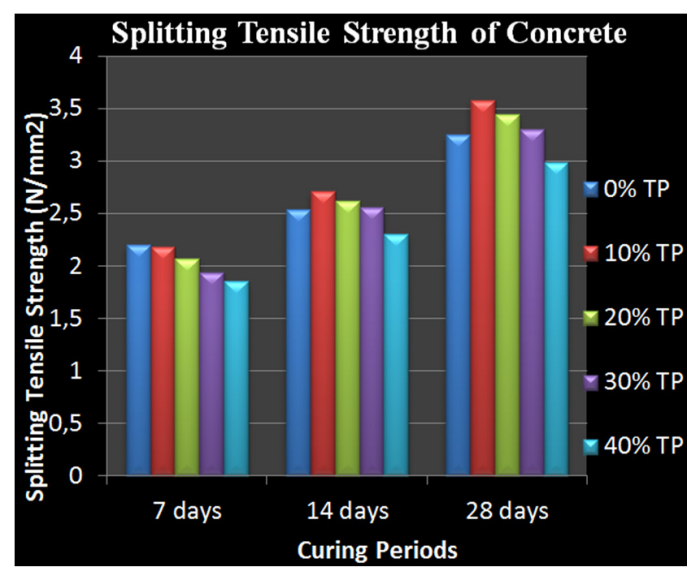

Fig. 3. Split tensile strength of concrete

\section{CONCLUSIONS}

- Maximum slump value was recorded as $88 \mathrm{~mm}$ at $40 \%$ of tile powder and minimum slump value was $58 \mathrm{~mm}$ at $0 \%$ of tile powder. It was observed that the workability of fresh concrete increased with the increase in the percentages of tile powder.

- The compressive strength of concrete improved by $7.50 \%$ with $10 \%$ of tile powder and decreased by $12.60 \%$ at $40 \%$ of tile powder used as a substitute for cement in concrete cured for 28 days. The compressive strength of concrete was reduced at the initial stage of the curing period and increased at the final stages of the curing period.

- Splitting tensile strength increased to $10.20 \%$ at $10 \%$ of tile powder and decreased to $8.0 \%$ at $40 \%$ tile powder used as cement replacement in concrete cured for 28 days.

\section{REFERENCES}

[1] S. Mindess, J. F. Young, D. Darwin, Concrete, Prentice Hall, 2003

[2] S. Ghosal, S. Moulik, "Use of rice husk ash as partial replacement with cement in concrete-A review", International Journal of Engineering Research, Vol. 4, No. 9, pp. 506-509, 2015

[3] N. D. Bheel, S. L. Meghwar, S. A. Abbasi, L. C. Marwari, J. A. Mugeri, R. A. Abbasi, "Effect of rice husk ash and water-cement ratio on strength of concrete", Civil Engineering Journal, Vol. 4, No. 10, pp. 2373-2382, 2018

[4] A. Goyal, A. M. Anwar, H. Kunio, O. Hidehiko, "Properties of Sugarcane Bagasse Ash and its Potential as Cement-Pozzolana Binder", Twelfth International Colloquium on Structural and Geotechnical Engineering, Ain Shams, 2007

[5] N. D. Bheel, F. A. Memon, S. L. Meghwar, I. A. Shar, "Millet Husk Ash as Environmental Friendly Material in Cement Concrete", 5th International Conference on Energy, Environment and Sustainable Development, Jamshoro, Pakistan, 2018

[6] N. D. Bheel, S. A. Abbasi, S. L. Meghwar, F. A. Shaikh, "Effect of Human Hair as Fibers in Cement Concrete", International Conference on Sustainable Development in Civil Engineering, Jamshoro, Pakistan, November 23-25, 2017

[7] S. A. Mangi, N. Jamaluddin, M. H. W. Ibrahim, N. Mohamad, S. Sohu, "Utilization of sawdust ash as cement replacement for the concrete production: A review", Engineering Science and Technology International Research Journal, Vol. 1, No. 3, pp. 11-15, 2017

[8] S. A. Mangi, M. H. W. Ibrahim, N. Jamaluddin, M. F. Arshad, F. A. Memon, R. P. Jaya, S. Shahidan, "A review on potential use of coal bottom ash as a supplementary cementing material in sustainable concrete construction", International Journal of Integrated Engineering, Vol. 10, No. 9, pp. 28-36, 2019

[9] V. R. Vummaneni, D. S. R. Murty, M. A. K. Reddy, "Study on strength and behavior of conventionally reinforced short concrete columns with cement from industrial wastes under uniaxial bending", International Journal of Civil Engineering and Technology, Vol. 7, No. 6, pp. 408417,2016

[10] N. Bheel, S. L. Meghwar, S. Sohu, A. R. Khoso, A. Kumar, Z. H. Shaikh, "Experimental study on recycled concrete aggregates with rice husk ash as partial cement replacement", Civil Engineering Journal, Vol. 4, No. 10, pp. 2305-2314, 2018

[11] N. Bheel, A. W. Abro, I. A. Shar, A. A. Dayo, S. Shaikh, Z. H. Shaikh, "Use of rice husk ash as cementitious material in concrete", Engineering, Technology \& Applied Science Research, Vol. 9, No. 3, pp. 4209-4212, 2019

[12] F. P. Torgal, S. Jalali, "Compressive strength and durability properties of ceramic wastes based concrete", Materials and Structures, Vol. 44, No. 1, pp. 155-167, 2011

[13] E. Fatima, A. Jhamb, R. Kumar, "Ceramic dust as construction material in rigid pavement", American Journal of Civil Engineering and Architecture, Vol. 1, No. 5, pp. 112-116, 2013

[14] V. S. N. V. L. Ganesh, N. C. Rao, E. V. R. Rao, "Partial replacement of cement with tile powder in M40 grade concrete", International Journal of Innovations in Engineering Research and Technology, Vol. 5, No. 7, pp. 34-39, 2018

[15] H. Dullah, Z. A. Akasah, N. M. Z. N. Soh, S. A. Mangi, "Compatibility Improvement Method of Empty Fruit Bunch Fibre as a Replacement Material in Cement Bonded Boards: A Review", IOP Conference Series: Materials Science and Engineering, Vol. 271, No. 1, Article ID 012076, 2017 
[16] I. S. Yadav, Laboratory Investigations of The Properties of Concrete Containing Recycled Plastic Aggregates, MSc Thesis, Thapar University, 2008

[17] M. Padma, M. N. Rao, "Influence of granite powder as partial replacement of fine aggregate and crushed tiles as coarse aggregate in concrete properties", International Journal for Modern Trends in Science and Technology, Vol. 3, No. 5, pp. 9-14, 2017

[18] C. H. Kumar, K. A. Ramakrishna, K. S. Babu, T. Guravaiah, N. Naveen, S. Jani, "Effect of waste ceramic tiles in partial replacement of coarse and fine aggregate of concrete", International Advanced Research Journal of Science, Engineering and Technology, Vol. 2, No. 6, pp. 1316,2015

[19] S. Aswin, V. Mohanalakshmi, A. A. Rajesh, "Effects of ceramic tile powder on properties of concrete and paver block", Global Research and Development Journal for Engineering, Vol. 3, No. 4, pp. 84-87, 2018

[20] I. B. Topcu, M. Canbaz, "Utilization of crushed tile as aggregate in concrete", Iranian Journal of Science \& Technology, Transaction B, Engineering, Vol. 31, No. B5, pp. 561-565, 2007

[21] S. A. Mangi, N. Jamaluddin, M. H. W. Ibrahim, A. H. Abdullah, A. S. M. A. Awal, S. Sohu, N. Ali, "Utilization of Sugarcane Bagasse Ash in Concrete as Partial Replacement of Cement", IOP Conference Series: Materials Science and Engineering, Vol. 271, No. 1, Article ID 012001, 2017 